\title{
REFERENCES
}

1. Canaan, T.-Die Lepra in Palaestina. Archiv fur Schiff- und Tropenhygiene, S. 21, H. 1, Bd. XXXI, 1927.

2. Elliot, R. H.-Ophthalmologie Tropicale. Traduction Francaise, 1922.

3. Fuchs, E-Lehrb. d. Augenheilk., S. 997, XIII Aufl., 1921.

4. Groenouw, A.-Beziehungen der Allgemeinleiden und Organerkrankungen zu Veranderungen und Krankheiten des Sehorgans. Abteilung 1. Graefe-Saemisch Handb. d. Augenheilk., III Aufl., 1920.

5. King, E.-The Eye in Leprosy. Brit.Jl. of Ophthal., Oct., 1936, p. 568.

6. Loehlein, W.-Operationen an den Augenlidern. Graefe-Saemisch Handb. d. Augenheilk. Augenaerztliche Operationslehre I, S. 162. Zweite und dritte Auflage, 1922.

7. Manson, S.-Tropical Diseases. X Edition, 1935.

8. Rogers, L.-Leprosy. Encyclopaedia Britannica, Vol. XIII, p. 957, 1929.

9. Willy, Alexander.-Spezielle Pathologie und Therapie innerer Krankheiten, herausgegeben von Friedrich Kraus und Theodor Brugsch. X Bd., 1 Teil.

\section{THE WATER-BINDING OF THE BRAIN}

BY

J. A. VAN HEUVEN and P. F. FischeR

UTRECHT

IN our last paper on "The Water-Binding of the Optic Nerve and of its Sheaths," we came to the conclusion that the optic nerve is capable of taking and keeping such quantities of water that this capability may play some part in the origin of a papilloedema. As the result of their pathologico-anatomical investigations in this field, Spatz and Marchesani came to the conclusion that papilloedema can be compared with the "Zysternenverquellung " which was seen by Spatz in the brains of patients suffering from brain tumour. If this conclusion is accurate it follows necessarily that the water-binding power of the brain tissue must be similar to that of optic nerve. Now it is a matter of common knowledge that brain tissue absorbs water, and the expression " oedema of the brain" is commonly used. In both this question, however, and in the use of the term " papilloedema" cne is inclined to think solely of the histological picture and not to consider the physico-chemical conditions.

Some investigations were made formerly by M. H. Fischer and his collaborators in the absorption of water by nervous tissues and brain tissues of rabbits. These authors worked with complete sets of brains, and their investigations were limited to a small number of experiments. They arrived at the important conclusion that brain tissues are quite capable of absorbing water, especially in weak acid solutions, and furthermore that an increase of weight of only 10 per cent. of brain tissue was sufficient to 
cause a fatal brain oedema. In order to obtain a clearer insight into the rôle played by the physico-chemical properties of the brain tissue in the pathogenesis of the papilloedema, we have performed the experiments which follow.

It speaks for itself, that brain substance as a whole shows a different behaviour from separate sections of the brain. In the same way the quantity of water which can be absorbed by a whole eye is quite different from that which can be absorbed by isolated parts of the eye. Investigations were made separately of the water-binding of the grey and of the white brain matter. It was impossible to say beforehand whether, e.g., the white brain tissue would react similarly in and from different anatomical situations in the same brain. We therefore aimed to take always the tissue from similar regions of the brain, doing so both in white and grey matter. Our white tissue was taken from the tissue between the internal capsule and cortex and our grey matter from the basal ganglia.

The second important fact was that for our investigations we had to limit ourselves to pieces as small as possible as to surface, weight and volume. We endeavoured to take pieces of brain as similar as possible in size to those from the optic nerve referred to in our paper on that subject (Brit. Jl. of Opthal., April, 1936). As we explained in the above-mentioned paper, it is important always to take pieces of tissue of the same size, as only by so doing are comparisons made possible. In order to make this paper a continuation of that on the optic nerve we acted as follows :-

Again we used ox brains, obtained as fresh as possible from the slaughter house and put these brain masses on their bases, cutting them into halves, by means of a large knife, in such a way that the basal ganglia were divided into equal parts. We took always first the white brain matter and after that the grey; in both cases small pieces of $2 \mathrm{~mm}$. thickness and $4 \mathrm{~mm}$. length. By doing so we got pieces of similar size and approximately similar weight to those taken from the optic nerve in our previous paper. These pieces were laid in little metal baskets, which were standing on a tripod in a weighing glass of known weight. As a matter of fact the same glasses were used, which we also used in our former experiments on the water-binding of the retina and of the optic nerve, which are described in our paper on the water-binding of the retina in the July, 1935, issue of this journal.

We took special care that the brains obtained were as fresh as possible, as we realised very soon that brain substances which are old or even brain substances which have been in the refrigerator for some time absorbed decidedly less water. This fact must be explained by the high quantity of acid the brain 
contains, making brain substance very much inclined to absorb water from its surroundings. Thus if the brain matter is not quite fresh, a considerable water-absorption will have already taken place. For the same reason brain substance which is not quite fresh is heavier than fresh.

As was done in our investigations into the water-binding of the retina and the optic nerve, we started our investigations on the water-binding of the brain by studying the water-absorption from pure water. Figure 1 shows our results. The ordinates show the percentage increase in weight through water absorption and the abscissae the time in hours. The diagram shows the conduct of the white and grey brain substances in distilled water and at the same that of the optic nerve, of the retina and of the sheaths of the optic nerve. Thus the difference in behaviour of the different tissues is shown clearly. It appears that the curve, which shows the water-absorption out of pure distilled water by the grey brain substance, is very similar to that of the optic nerve. The optic nerve takes a higher percentage of water than the grey matter, and a much lower percentage than the white matter. The water-binding of the sheath is absolutely and relatively much greater than that of all other tissues, and conversely the water-binding of the retina is both absolutely and relatively the smallest.

Observing the behaviour of the different tissues within the first few hours, we find the following series:-

Sheath of the optic nerve larger than optic nerve. Optic nerve larger than white brain matter. White brain matter larger than grey brain matter. Grey brain matter larger than retina.

In this series the tissues with the greatest water-binding power are given on the left hand and those with the smallest waterbinding power on the right. The percentage of difference is greatest between retina and sheath of the optic nerve and is as much as 64 per cent. This figure represents between optic nerve and retina 39 per cent., between optic nerve and grey brain matter 23 per cent. and between white and grey brain matter 8 per cent.

Based upon these investigations we conducted further experiments tracing the conduct of the brain in acid. Again we used the same acids in the same concentrations as we used previously, in dealing with retina and optic nerve. The only difference in comparison with the optic nerve is, that in the next diagram the figures mentioned are not those found after 3 hours but those found after 24 hours. This could easily be done as in dealing with brains we had much more material at our disposal than in dealing with previous tissues. This means that we have done our tests after one, three, six and 24 hours respectively, but the diagram 
shows that the figures found after 24 hours were in logical agreement with those after one, three and six hours. Seeing we obtained such a regular curve as is shown in Figure 1, we kept all our small sections of tissue in the different bathing liquids for 24 hours after our first preliminary experiment. In this way we were able to check our totals after 24 hours, and this explains why we show these figures.

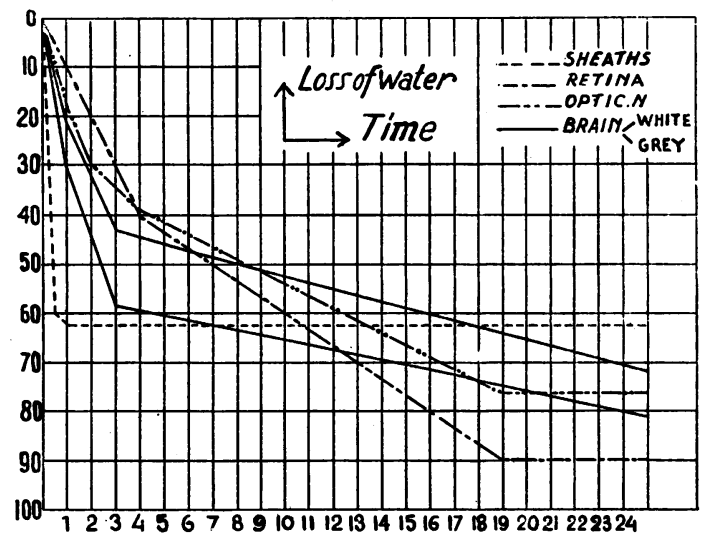

Diagram I.

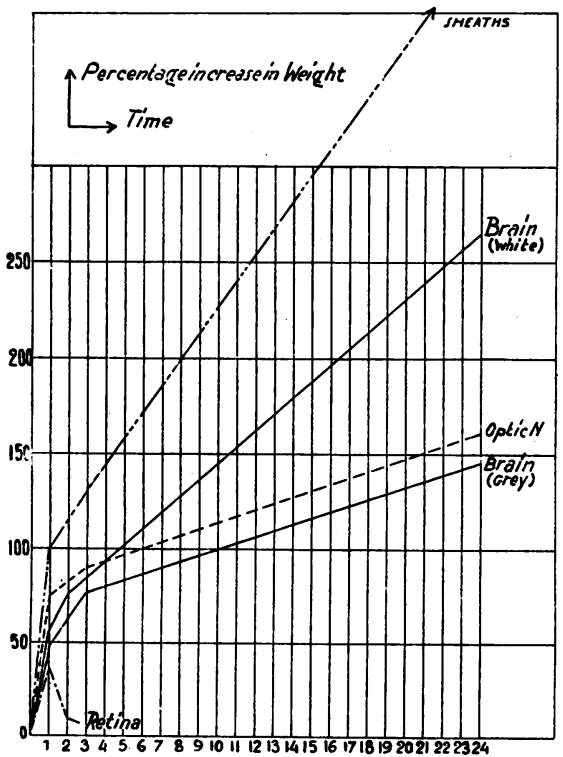

DiAGRAM II. 
In every experiment we took two pieces of the tissue and kept them under the same conditions. The figures in the next schedule are averages, given in such a way that every figure, which was used for the calculation of an average was in itself already an average of two experiments. The numbers shown in this schedule, therefore, are the averages of at least sixteen experiments.

\section{SCHEDULE I}

\begin{tabular}{lll|c|c|c|c|c|c|c|c|c|c} 
& & $\mathrm{n}$ & $\mathrm{n} / 10$ & $\mathrm{n} / 100$ & $\mathrm{n} / 1000$ & $\mathrm{H} 2 \mathrm{O}$ & $\mathrm{n}$ & $\mathrm{n} / 10$ & $\mathrm{n} / 100$ & $\mathrm{n} / 1000$ & $\mathrm{H} 2 \mathrm{O}$ \\
\hline Hydrochlorid acid & $\ldots$ & +15 & +38 & +70 & +90 & - & +24 & +45 & +60 & +99 & - \\
Sulphuric acid & $\ldots$ & +18 & +20 & +29 & +40 & & +0 & +4 & +17 & +38 & \\
Nitric acid & $\ldots$ & $\ldots$ & +27 & +69 & +82 & +100 & - & +12 & +55 & +49 & +36 & - \\
Acetic acid & $\ldots$ & $\ldots$ & +25 & +18 & +43 & +128 & - & +23 & +24 & +29 & +74 & - \\
Lactic acid & $\ldots$ & $\ldots$ & +94 & +51 & +90 & +225 & - & +76 & +71 & +89 & +88 & - \\
Citric acid & $\ldots$ & $\ldots$ & +92 & +25 & +40 & +97 & - & +56 & +63 & +84 & +98 & - \\
\hline
\end{tabular}

In the schedule the left series of figures shows the percentage of weight increase due to water-binding of the white brain matter, and the right series of figures shows the same of the grey matter. We were satisfied with the results given from four different concentrations, because from these the conduct of the brain in acid was quite clear. The last column shows the percentage of increase in weight in pure water.

Schedule I shows that the water-binding in acid is less than that in pure water, and that equal normal acids show a different water-binding. Generally speaking the water-binding is greater in inorganic acids as compared with mineral acids and furthermore, there is an increase of the water-binding when the concentration decreases. As a rule the white brain substance absorbs more water than the grey matter. Especially in lactic acid is the white matter inclined to take much water, and in a concentration of 0.001 normal it takes a percentage of water which exceeds 200 per cent. This is even more in still weaker concentrations. This specific conduct in lactic acid may be of some biological importance.

In a second series of tests we took small pieces of brain substance and kept them in solutions of alkalies. Schedule II shows, that in alkalies brain substance is quite capable of taking water. Furthermore, that in equinormal solutions of alkalies the waterbinding is shown differently, and that the quantity of water-bound 
increases with increasing concentrations. Here again the white brain matter shows a greater water-binding than the grey. In normal concentrations the water-binding was so great that it could be no longer accurately measured. This is expressed in the schedule by a line, showing that it was no longer possible to weigh the small pieces of brain substance without losing part of them.

SCHEDULE II

\begin{tabular}{ll|c|c|c|c|c|c|c|c|c|c}
\hline & & $\mathbf{n}$ & $\mathbf{n} / 10$ & $\mathbf{n} / 100$ & $\mathbf{n} / 1000$ & $\mathrm{H} 2 \mathrm{O}$ & $\mathrm{n}$ & $\mathrm{n} / 10$ & $\mathbf{n} / 100$ & $\mathbf{n} / 1000$ & $\mathrm{H} 2 \mathrm{O}$ \\
\hline $\mathrm{NaOH}$ & $\ldots$ & - & +270 & +213 & +107 & - & - & +184 & +94 & +35 & - \\
$\mathrm{KOH}$ & $\ldots$ & - & +264 & +244 & +186 & +264 & - & +165 & +65 & +62 & +135 \\
$\mathrm{NH}_{3}$ & $\ldots$ & - & +287 & +297 & +280 & - & - & +188 & +129 & +81 & - \\
\hline
\end{tabular}

After this we made some tests in solutions of salt. In doing so we first took a series of cations and after that a series of anions. Only the latter are shown in the form of a schedule, as the former gave the same results. The results are shown in schedule III.

SCHEDULE III

\begin{tabular}{l|r|r|r|r|r|r|r|r|r|c}
\hline & $\mathrm{m}$ & $\mathrm{m}^{\prime} 10$ & $\mathrm{~m} / 100$ & $\mathrm{~m} / 1000$ & $\mathrm{H} 2 \mathrm{O}$ & $\mathrm{m}$ & $\mathrm{m} / 10$ & $\mathrm{~m} / 100$ & $\mathrm{~m} / 1000$ & $\mathrm{I} \mathbf{2}_{2} \mathrm{O}$ \\
\hline Na-cyanide ... & +20 & +53 & +114 & +104 & - & +3 & +29 & +68 & +69 & - \\
Na-rhodanide & +34 & +38 & +81 & +113 & - & +29 & +45 & +54 & +79 & - \\
Na-nitrate ... & +33 & +44 & +86 & +231 & - & +31 & +37 & +51 & +97 & - \\
Na-iodide ... & +39 & +35 & +80 & +88 & & +29 & +30 & +69 & +80 & +135 \\
Na-bromide... & +30 & +26 & +51 & +53 & - & +22 & +28 & +62 & +57 & - \\
Na-tartrate ... & -4 & +29 & +76 & +85 & - & -8 & +17 & +51 & +67 & - \\
Na-phosphate & -3 & +12 & +59 & +120 & - & +0 & +15 & +55 & +61 & - \\
Na-sulphate & -2 & +33 & +37 & +70 & - & -3 & +24 & +56 & +68 & - \\
Na-citrate ... & -7 & +15 & +72 & +92 & - & -9 & +25 & +56 & +78 & - \\
\hline
\end{tabular}

From this it is evident, that in solutions of salt the water-binding from pure water is checked, and that proportionately to their concentrations. This checking influence of salt solutions is greater in the grey brain matter than in the white. 
Equimolar salt solutions show a different influence. It is possible to arrange a series according to Hofmeister. This series shows different figures for white and grey brain matter respectively. Though the figures for white brain substance are not quite similar to those of the optic nerve they very much resemble these. Nearly the same results were obtained with anelectrolytes. Anelectrolytes also check the water-binding according to the concentration. Equimolar solutions show a different influence, and in these cases checking is greater for the grey brain matter than for the white.

From these series of experiments we may conclude, as could be expected, that the white and grey brain matters are capable of binding water, and that this water-binding is a real " Quellung." The capacity for water-binding is considerable; it is larger in the white brain matter than in the grey, and the capacity of the white brain matter is almost equal to that of the optic nerve. One might say that in these experiments the relation between the optic nerve and the white brain matter is once more shown.

For the purpose of the measuring the intensity of the waterbinding we have made use of solutions of acetone and urea, as we did in our former paper. Schedules V and VI show that the water-binding out of acetone is small, even in a concentration as high as 15 per cent. after one hour. The same can be said of urea.

SCHEDULE IV

\begin{tabular}{|c|c|c|c|c|c|c|c|c|c|c|}
\hline & $\mathrm{m}$ & $\mathrm{m} / 10$ & $\mathrm{~m} / 100$ & $\mathrm{~m} / 1000$ & $\mathrm{H}_{2} \mathrm{O}$ & m & $\mathrm{m} / 10$ & $\mathrm{~m} / 100$ & $\mathrm{~m} / 1000$ & $\mathrm{H}_{2} \mathrm{O}$ \\
\hline Urea ... & +172 & +125 & +130 & +123 & & +103 & +125 & +113 & +116 & - \\
\hline Glucose & +154 & +147 & +177 & +215 & +264 & +36 & +71 & +109 & +124 & $+\underline{-135}$ \\
\hline Saccharose ... & +23 & +41 & +67 & +112 & - & +3 & +46 & +53 & - & - \\
\hline
\end{tabular}

SCHEDULE V

Concentration of Acetone

\begin{tabular}{r|r|r|r|r|r|r|r|r|r|r}
\hline Time in minutes & $10 \%$ & $20 \%$ & $30 \%$ & $40 \%$ & $50 \%$ & $10 \%$ & $20 \%$ & $30 \%$ & $40 \%$ & $50 \%$ \\
\hline 1 minute & +6 & +6 & +6 & +4 & +3 & +5 & +6 & +4 & +6 & +2 \\
5 minutes & +6 & +6 & +4 & +3 & +4 & +8 & +5 & +4 & +4 & +4 \\
10 minutes & +9 & +10 & +7 & +10 & +5 & +10 & +10 & +8 & +7 & +7 \\
60 minutes & +29 & +23 & +16 & +11 & +8 & +16 & +20 & +17 & +14 & +12 \\
\hline
\end{tabular}


SCHEDULE VI

Concentration of Urea

\begin{tabular}{c|c|c|c|c|c|c|c|c|c|c}
\hline Time in minutes & $10 \%$ & $20 \%$ & $30 \%$ & $40 \%$ & $50 \%$ & $10 \%$ & $20 \%$ & $30 \%$ & $40 \%$ & $50 \%$ \\
\hline 1 minute & +6 & +3 & +3 & +6 & +3 & +2 & +2 & +2 & +2 & +4 \\
5 minutes & +4 & +6 & +7 & +6 & +6 & +6 & +5 & +4 & +5 & +5 \\
10 minutes & +12 & +11 & +15 & +11 & -9 & +9 & +7 & +5 & +7 & \pm 0 \\
60 minutes & +22 & +22 & +29 & +14 & -12 & +10 & +13 & +9 & +4 & -2 \\
\hline
\end{tabular}

SCHEDULE VII

\begin{tabular}{|c|c|c|c|c|c|c|c|c|}
\hline \multirow{2}{*}{$\begin{array}{c}\text { Time in } \\
\text { minutes }\end{array}$} & \multicolumn{2}{|c|}{$75 \%$ Acetone } & \multicolumn{2}{|c|}{$100 \%$ Acetone } & \multicolumn{2}{|c|}{$75 \%$ Acetone } & \multicolumn{2}{|c|}{$100 \%$ Acetone } \\
\hline & $\begin{array}{l}\text { Loss of } \\
\text { water }\end{array}$ & $\begin{array}{c}\text { Percent- } \\
\text { age of } \\
\text { water. }\end{array}$ & $\begin{array}{l}\text { Loss of } \\
\text { water }\end{array}$ & $\begin{array}{c}\text { Percent- } \\
\text { age of } \\
\text { water } \\
\end{array}$ & $\begin{array}{l}\text { Loss of } \\
\text { water }\end{array}$ & $\begin{array}{c}\text { Percent- } \\
\text { age of } \\
\text { water }\end{array}$ & $\begin{array}{l}\text { Loss of } \\
\text { water }\end{array}$ & $\begin{array}{c}\text { Percent- } \\
\text { age of } \\
\text { water } \\
\end{array}$ \\
\hline 1 minute & \pm 0 & 68 & -1 & 67 & +2 & 75 & -9 & 76 \\
\hline 5 minutes & \pm 0 & 67 & -5 & 69 & +1 & 73 & -16 & 71 \\
\hline 10 minutes & -2 & 68 & -7 & 70 & +1 & 72 & -42 & 74 \\
\hline 60 minutes & -3 & 70 & -27 & 68.5 & +1 & 74 & -49 & 74 \\
\hline
\end{tabular}

In the next series of experiments we put pieces of white and grey brain matter in concentrations of 75 per cent. and 100 per cent. acetone and measured their water-percentages for a time. These are shown in schedule VII. From this schedule it is quite clear that in the space of one hour pure acetone is capable of extracting from the white brain substance $2 \tau$ per cent. of its water content. It must be borne in mind that normally the white brain substance has a water-percentage of about 68/69 per cent. In experimenting similarly with grey brain matter, 49 per cent. is lost, while the normal water-percentage is 74 per cent. The waterbinding of the white brain substance appears to be almost similar to that of the optic nerve, both in manner of binding and in quantitative conditions.

Furthermore we have measured the change in the specific weights, as was done formerly with the other tissues of the eye. We found that in using white and grey brain matter, the specific weight increases gradually and slowly when the water-percentage is diminished. In our paper on the "Water-binding of the Optic Nerve and its Sheath" Diagram I shows the relations between retina and optic nerve in this respect. From this diagram it 
appears clearly that the specific weight of the optic nerve is a little less than of the retina; but if the water-percentage of the optic nerve decreases the specific weight increases in a straight line. In the retina this increase is very rapid and great: this is shown in the curve. If we try to draw our results for white and grey brain matter in this diagram, we get two lines, which are almost exactly similar. The increase amounts from 1.05 to 1.1 when the water-percentage is decreased from 74 rasp. 68 to 0 . From this it is quite clear that the water-binding of the optic nerve must be similar to that of the brain.

Finally we endeavoured to measure the rapidity of the loss of water on desiccation. Figure 2 shows the results. The ordinates show the percentage of loss of water, the abscissae the time in hours. Diagram. II shows 5 curves representing the loss of water in relation to the time of desiccation at the temperature of $68 \cdot 6^{\circ} \mathrm{F}$. of the sheath of the optic nerve, white brain matter, grey brain and retina. This series shows directly an increase in rapidity of loss of water. Diagram II shows that the intensity of waterbinding is smallest in the sheath of the optic nerve and brain matter, optic nerve and retina. This series shows directly an increase in rapidity of loss of water. Diagram II shows that the intensity of water-binding is smallest in the sheath of the optic nerve, largest in the retina and almost equal in the optic nerve and brain matter. The percentage of water shows a quite reverse figure. The water-percentage is largest in retina, less in white brain matter, optic nerve, grey brain matter and sheath of the optic nerve.

Summarising one may say that brains show the capacity of water-binding by "Quellung." The capacity, intensity and form of the water-binding are similar to those of the optic nerve.

The optic nerve is more closely connected with the white brain matter than with the grey. In regard to the pathogenesis of the papilloedema, our experiments show that one may expect that changes in the conditions which have some influence upon the brain matters may also show changes of the optic nerve. In other words, it can be expected that by increase of the power of water-binding a condition can be created which appears as a papilloedema, while at the same time the brain matters show a condition of swelling. 